\title{
XLVIII.-New determination of the proportions of the constituents of water; and the density of certain elastic fluids
}

\section{M.M. Berzelius \& Dulong}

To cite this article: M.M. Berzelius \& Dulong (1821) XLVIII.-New determination of the proportions of the constituents of water; and the density of certain elastic fluids, Philosophical Magazine Series 1, 58:281, 203-208, DOI: 10.1080/14786442108652607

To link to this article: http://dx.doi.org/10.1080/14786442108652607

曲 Published online: 27 Jul 2009.

Submit your article to this journal $\pi$

Џll Article views: 2

Q View related articles $\sqsubset$ 
when the water was poured out it effervesced like mineral water.

Thus it would appear that the mode adopted by Mr. Perkins in these experiments, was rather inadequate to the purpose he had in view. I would therefore, in conclusion, suggest, that in any future trials he may be disposed to make, he should previously fill the bottles to the bottom of the corks with water, that the whole of the air may be removed: and, to render the result still more conclusive, the bottles ought to be inclosed in a cage of iron or copper. After these precautions, should he find that the bottles were broken when brought up, he might then justly conclude, that the re-expansion of the compressed water had been the cause, since the counter-resistance of the water within, must have presented the effect of pressure from without so considerably as to prevent the breaking of the bottles from that direction: the only way, therefore, in which they could be broken, would be by the external column of water compressing the confined portion, and forcing an additional quantity into the interior: and by this again resuming its former volume when the acting pressure is diminished.

I remain, dear sir,

Yours respectfully,

John Deuchar.

XLVIII.-New Determination of the Proportions of the Constituents of Water; and the Density of certain Elastic Fluids. By MM. Berzelius and Dulong *.

A

$s$ modern chemists in their analyses claim a degree of accuracy embracing the thousandth part of the elements employed, it is evident that the fundamental data from which they make their deductions should be free from that degree of error which they profess themselves able to avoid in their experiments. Of these data, that of the constitution of water is one of the most important, and the most frequently employed. The proportions generally adopted of late years have appeared to be beyond suspicion of error, both.by the means employed to obtain them, and the ability of the observers who have conducted them. But we have had some reason to believe that this number was liable to be affected by some slight error ; and as the subject was of considerable importance, we resolved to conduct, in concert, the experiments necessary to ascertain this point. M. Berthollet, whose liberality has so often been useful to science, gave us

* From the Annales de Chimie et do Physique.

C c 2

every 
every possible facility in our design, by putting at our disposal the daboratory of Areueil.

The apparatius employed in the first experiments on the composition of water, did not allow of that precision which is notr required in chemical analysis. But the fact being once established, that water is the result of the combination of oxygen and hydrogen, the knowledge of the precise proportions required only two facts to be determined; namely, the relative volumes of the two elements, and their specific gravities. The latter, being indispensable in a variety of researches, were already known; and for the former, Volta's eudiometer was sufficient. The greatest confidence was justly reposed on this method, after Messrs. GayLussac and Humboldt had shown, in their masterly Memoir on Eudiometry, the true proportions, in volume, of the constituents of water; and after Messrs. Biot and Arrago had applied the most minute attention to the determination of the specific gravity of the greater number of the gases.

If the proportion of hydrogen deduced from these results, namely, 13.27 per cent., was erroneous, the error was in estimating the specific gravity of either the hydrogen or the oxygen, or both ; for the computation of respective volumes has this remarkable advantage, that, being dependent on a general law, it is incapable of error. Before we entered on new observations on the densities of oxygen and hydrogen, we wished to obtain, by a simple method, the confirmation of our doubts. The decompesition of an oxide by hydrogen appeared to us the most accurate and convenient way; and we arlopted the following precautions to render the experiment conclusive :

We first procured perfectly pure hydrogén gas. Distilled zine is not preferable for this object to common zinc, for they both contain the same impurities; namely, lead, tin, copper, iron, cadnium, and sulphur; but on passing the hydrogen through a tube containing fragments of caustic potash slightly moistened, the gas loses its odour completely, and comes out perfectly pure:

Hydrogen gas, obtained by the action of diluted sulphuric acid on zinc, was purified by sending the current through moistened fragments of caustic potash. It was then dripd by being trans. mitted through muriate of lime; after which it was placed in contact with oxide of copper dried and inclosed in a tube, which was united to the apparatus by two tubes of elastic gun, which allowed us to weigh it accurately both before and after the experiment. When the hydrogen had passed in sufficient quantity to expel the atmospheric air, the oxide of copper was heated by a spirit lamp. In the first experiments, the greater part of the newly generated water was received in a liquid state in a small

reci- 


\section{of the Constiluents of Water, \&c.}

recipient attached to the above-mentioned tube, in order to allow us to examine its purity : in the subsequent ones, the aquaus vapour and the excess of the hydrogen passed through a long column of fused muriate of lime. It is easy to see of how much precision this mode of performing the experiment is capable: Hence the results obtained in the several trials differ bit little from each other; and as we were not able to detect any impurity in the water produced, we may consider the following numbers expressing as exactly as possible the composition of this fluid.

Froin the mean of three experiments it appears that 100 parts by weight of oxygen unite with 12.488 of hydrogen to produce water; which is equivalent to 38.9 per cent. of oxygen; with H.I of hydrogen. Whereas the number formerly assumed as the proportion of hydrogen to 100 of oxygen, is 13.27 instead of 12.488 , which makes a difference of nearly a twelfth part. We can therefore no longer doubt the reality of the error which we had suspected; but it became necessary to examine the cause of it; by taking anew the densities of oxygen and hydrogen, which we performed in the usual methods, adopting, however, the following precautions, which appear to us of so much importance as to deserve a particular notice.

It has been proved by Mr. Dalton, that no gas insoluble in wat ter can remain confined in contact with this liquid, even for a short time, without absorbing a certain quantity of the gaseous mixture which water always holds in solution. When the density of the confined gas does not materially differ from that of atmospheric air, the addition of the gas which is absorbed from the water produces no material error; but where the confined gas is hydrogen, in particular, it is obvious that an alloy of no more than a hundredth part will produce a prodigious error in the estimated specific gravity. It is very probahle that to this cause (which was not known to Messrs. Biot and Arrago) we must attribute the error that affects the number which they have given for the density of hydrogen. We have avoided it by covering the surface of the water that confines it with a stratum of fixed oil, which, as it is well known, makes the passage of the gas from the water much more difficult. We have operated and given the results of our experiments both on dried gas, and on gas saturated with moisture. One may employ either of them indifferently, particularly when the external temperature is not very high. However, it has appeared to us that the observations made on the gases artificially dried accorded better with each other. Not that there is any uncertainty in the data, on which are founded the corrections that must be made for aqueous va- 
pour; but that, in passing the humid gases from the jar to the balloon glass, it is difficult entirely to avoid the condensation of a minute portion of aqueous vapour, when the sudden expansion of the transferred gas causes a reduction in its temperature.

M. Biot, to avoid long calculations, and corrections, often un= certain, has proposed to weigh the exhausted balloon both before and after the weighing of the gas, and to take the mean of these two determinations as the true weight of the balloon at the moment in which it is weighed full of the elastic fuid. For this.proceeding to be accurate, the atmospheric changes must go on uniformly, and the first and third weighings should be made at a distance of time nearly equal to the, intermediate weighing. For short intervals, this method is not exposed to the risk of any im. portant error ; but when elastic fluids obtained by long and diffienlt processes are operated upon, a considerable time inay elapse between the first and the second weighing, and during the double of this interval, the uniformity of the variations may no longer have taken.place. We therefore preferred taking the weight of the exhausted balloon inmediately after each weighing of it when full of the required gas. A few minutes are. sufficient to make the vacuum, and during this short interval, it is very rare that any change in the circumstances of the atmosphere can occur.

The following observations relate to oxygen, hydrogen, azote, and carbonic acid : The oxygen was extracted from chlorate of putash, and was passed through a strong solution of caustic potash, to extract any portion of carbonic acid with which it might be contaminated. The method of obtaining hydrogen has been already described. The carbonic acid disengaged from white marble by means of nitric acid, was made to traverse a long column of powdered crystals of subcarbonate of soda before it reached the vessel that was to receive it. Lastly, the azote was obtained by decomposing ammonia by chlorine, and passing the gas through an acid and an alkaline solution alternately.

The following are the results of the specific gravities of the gases according to our experiments, the gases being perfectly dry, and atmospheric air being $=1.000$.

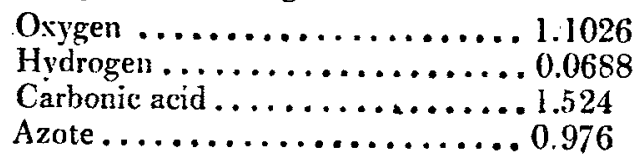

The gravities of the same gases, as determined by Messrs. Biot and Arrago, are as follows: 


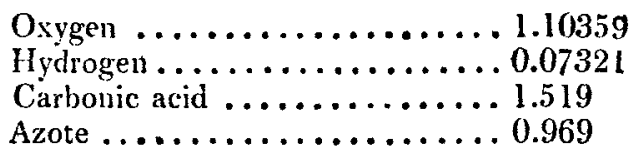

If we take the above proportions in weight of the elements of water, and take the density of oxygen as obtained by our experiments at 1.1026 , the specific gravity of the hydrogen will turn out to be $0.06 \mathrm{S8}$, but by direct experiment it gave us 0.0687 .

It appears, then, that the greatest difference between our results and those of Messrs. Biot and Arrago relates to the density of hydrogen; which confirms what we have said above on the cause of this difference. The increase in the number which we have given for carbonic acid, though small, is sufficient, however, to influence in a sensible manner the number expressing the density of the vapour of carbon on account of its levity; and it appears to us to accord better with the results of the analysis of vegetable substances. Lastly, the density of azote, calculated from our observations, approaches more nearly to that which is deduced from the composition of the nitrates.

For the convenience of those who engage in analytical researches, we have collected in the following table the densities and proportions by weight of several compounds calculated from the bases above given. These numbers should be preferred to those that are obtained by direct analysis, which hardly ever bear the same degree of approximation that may be obtained by inference from the above-mentioned data.-Before we conclude, we may observe that our new results differ but little from those which are given in an anonymous memoir, inserted in the Annals of Philosophy for November. 1815 and February 1816; but the English author has added no observations, and the hypotheses which have served him to correct the established numbers being absòlutely gratuitous or false; no confidence can be placed in his results. 


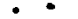

$\infty$

\section{䓪}

ธ.

స1

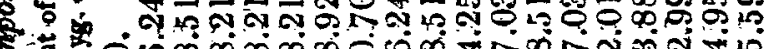
落 ช तु

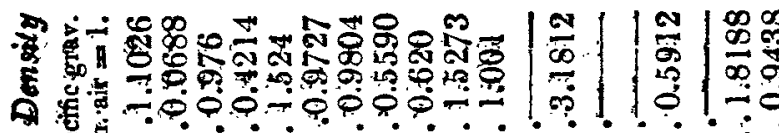

के 